\title{
Aggregate size effect on the water retention properties of a lime-treated compacted silt during curing
}

\author{
Yejiao Wang ${ }^{1}$, Yu-Jun Cui ${ }^{1, a}$, Anh Minh Tang ${ }^{1}$, and Nadia Benahmed ${ }^{2}$ \\ ${ }^{1}$ Ecole des Ponts ParisTech, U.R. Navier/CERMES, 6 - 8 av. Blaise Pascal, Cité Descartes, Champs - sur - Marne, 77455 Marne - la - \\ Vallée cedex 2, France \\ 2 IRSTEA, Groupe de Recherche "Ouvrages hydrauliques", 3275 route Cézanne, CS 40061, 13182 Aix En Provence Cedex 5, France
}

\begin{abstract}
The main drying paths of the water retention curves of lime-treated soils were measured. Aggregate size effect on the water retention property was emphasised. Four soil powders with different maximum aggregate sizes $\left(D_{\max }=5,2,1\right.$ and $\left.0.4 \mathrm{~mm}\right)$ were prepared and mixed with $2 \%$ quicklime (by weight of dry soil). Samples were prepared by static compaction at dry side of optimum water content $(w=17 \%)$ with a dry density of $1.65 \mathrm{Mg} / \mathrm{m}^{3}$. Suction measurement was performed by a dew-point hygrometer at different curing periods ( $t=7,28$ and 90 days). The results obtained show that: i) aggregate size effect is insignificant on the water retention curve of untreated soil in the studied suction range (ca $500 \mathrm{kPa} \sim 55 \mathrm{MPa}$ ); ii) lime treatment gradually improves the soil water retention capacity with the increasing of curing time; iii) aggregate size effect on water retention property of lime-treated soil becomes significant in the suction range from ca $860 \mathrm{kPa}$ to $9 \mathrm{MPa}$ on the long curing term: treated soils prepared with smaller aggregate size (S0.4 and S1) have a higher water retention capacity rather than soils prepared with larger aggregate size (S5).
\end{abstract}

\section{Introduction}

Lime treatment could effectively improve both the workability and mechanical behaviours of problematic soils [1-6]. When quicklime $(\mathrm{CaO})$ is added into humid soil and mixed together, hydration of quicklime takes place immediately with heat release. Then the calcium ions $\left(\mathrm{Ca}^{2+}\right)$ from ionization reactions of the calcium hydroxide $\left(\mathrm{Ca}(\mathrm{OH})_{2}\right)$ in the pore water would react with clay subsequently. There are two main different reactions could take place in the soil-lime-water system: cation exchange in short curing time and pozzolanic process on the long term. Cation exchange induces the flocculation and agglomeration of soil particles, which modify the soil workability. Cementitious compounds generated in the pozzolanic process, significantly contribute to the strength gain by bonding the soil particles together. This process is time-dependent.

Recently, more attentions have been paid to the efficiency and durability of lime treatment. Loss of efficiency and poor durability of treated soils in the field conditions were reported. Generally, field samples have higher hydraulic conductivity, lower strength and stiffness $[5,7,8]$. Besides of several environmental factors, such as heat transfer and wetting/drying cycles, another essential factor can be the aggregate size [5]. Indeed, nature soils in the laboratory are usually first airdried, and then grounded into few millimetres. After that the prepared soil powders are mixed with lime and water. Nevertheless, it is important that the soil aggregate size in

\footnotetext{
a Corresponding author: yu-jun.cui@enpc.fr
}

the field condition could reach several centimetres before lime treatment. Tang et al. [5] also pointed out that the lime-treated soil prepared with larger aggregate had a lower stiffness and higher sensitive to the wetting/drying cycles simulating the climate changes.

Water retention property is an essential parameter to describe the hydro-mechanical behaviour of untreated soils. Numerous studies showed that the water retention capacity of lime-treated soil was increased with curing time $[2,9,10]$. However, still few works focusing on the aggregate size effect on the water retention capacity of treated soils have been reported. This constitutes the main objective of this study.

\section{Materials and methods}

Studied soil was a plastic silt, with $27 \%$ clay-size fraction. Its main minerals are quartz $(55 \%)$, kaolinite $(12 \%)$, feldspars $(11 \%)$, illite $(10 \%)$, goethite $(6.5 \%)$, montmorillonite $(4 \%)$, chlorite $(1 \%)$ and rutile $(0.5 \%)$ [11]. More details about the geotechnical properties of this silt are indicated by Wang et al. [12]. Nature soil was first air-dried, ground and passed through four target sieves in order to get four kinds of powders with different maximum aggregate sizes, namely S5, S2, S1 and S0.4 (as shown in Figure 1). In detail, $D_{\max }$ is $5 \mathrm{~mm}$ for $\mathrm{S} 5,2$ $\mathrm{mm}$ for $\mathrm{S} 2,1 \mathrm{~mm}$ for $\mathrm{S} 1$, and $0.4 \mathrm{~mm}$ for S0.4. Initially, dry soils were mixed with $2 \%$ of quicklime thoroughly, and then the mixture were humidified with distilled water 
to reach the target water content ( $w=17 \%$, dry of optimum) and compacted statically to reach the target density $\left(\rho_{d}=1.65 \mathrm{Mg} / \mathrm{m}^{3}\right)$. Immediately after compaction, samples were carefully covered by plastic films, sealed in a plastic box and cured for a certain period ( $t=7,28$ or 90 days). At each curing time, one sample was cut into more than 8 small pieces. They were air-dried for different durations, in order to obtain different suction values. Afterwards, they were covered again for over-night water homogenisation. Suction measurement was performed at the second day by using the WP4 dew-point hygrometer. After suction measurement, water content was determined by $105^{\circ} \mathrm{C}$ oven-drying.

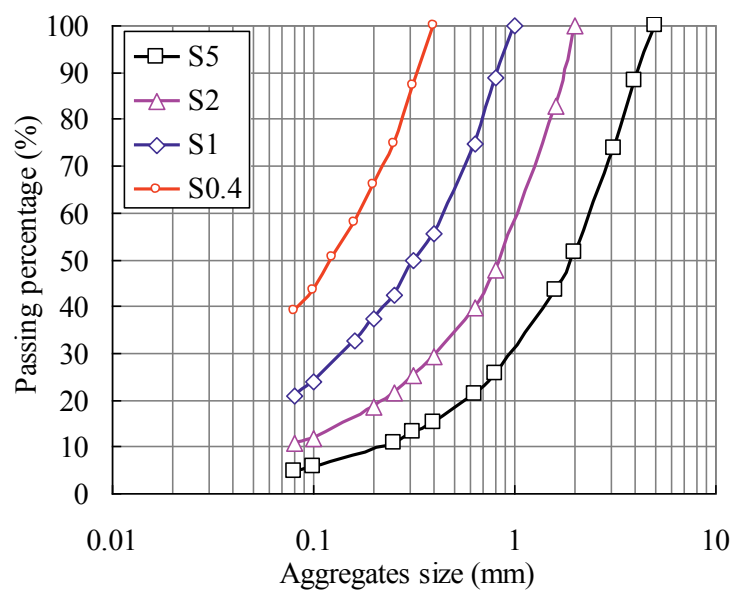

Figure 1. Aggregate size distributions of the four soil powders (S0.4, S1, S2 and S5) by the dry sieving method.

\section{Experimental results}

As shown in Figure 2, water retention curves of four different untreated soils are plotted together. Different soils with different aggregate sizes present a similar linear water retention curve in terms of water content in the semi-logarithmic scale. It indicates that aggregate size effect is insignificant for untreated soil during this measured suction range (from ca $500 \mathrm{kPa}$ to $60 \mathrm{MPa}$ ).

By contrast, water retention curves of treated soils at different curing durations are plotted in Figure $3 a, b$ and $\mathrm{c}$, respectively. At the curing time of $t=7$ days, aggregate size effect is still not so obvious to be distinguished. However, the water retention curves of treated soils after 7 days' curing are located just slightly above that of untreated soils, in a suction range of ca $1300 \mathrm{kPa}$ to 5500 $\mathrm{kPa}$. This indicates that the water retention capacity of lime-treated soil after 7 days' curing is slightly increased.

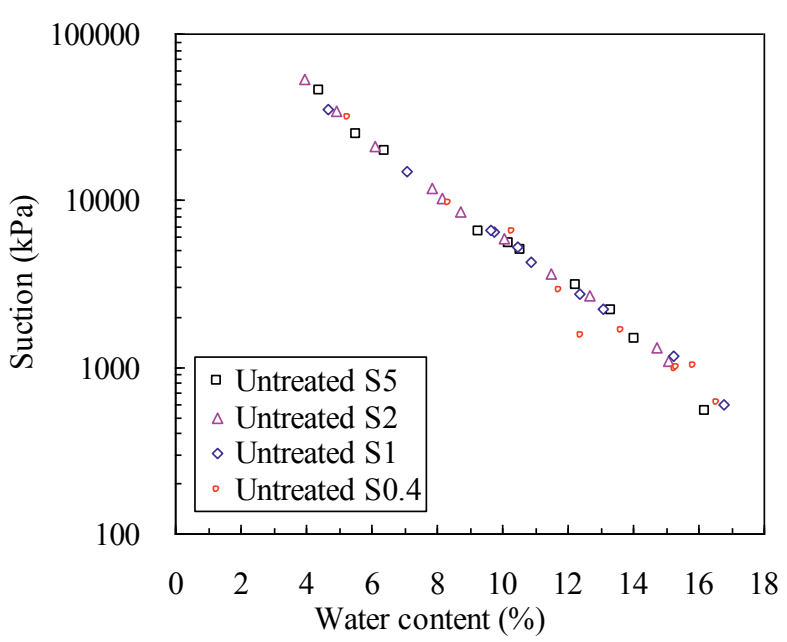

Figure 2. Water retention curves of untreated soils with different aggregate sizes.

With the increase of curing time, water retention abilities of treated soils are continually improved. Simultaneously, the water retention curves gradually form an S-shaped character. At the curing time of $t=28$ days, suction difference in the range from ca $960 \mathrm{kPa}$ to $7200 \mathrm{kPa}$ is getting larger between the treated soils and untreated soils. Moreover, this suction difference deepens at a curing time of $t=90$ days. Obviously, aggregate size effect is significant on the long curing term: samples prepared with smaller aggregates (S0.4 and S1) have a relatively higher water retention capacity rather than that with larger aggregates (S5), especially in the suction range from ca $860 \mathrm{kPa}$ to $9 \mathrm{MPa}$. Nevertheless, in the higher suction range (more than $13 \mathrm{MPa}$ ), no evident aggregate size effect is observed, neither a visible difference between the water retention curve of treated soils and that of untreated soils.

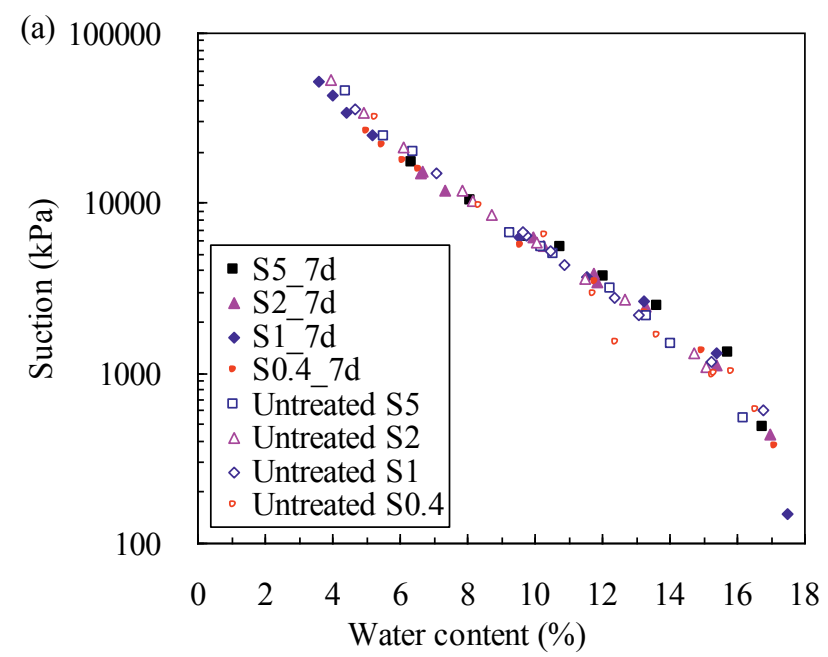




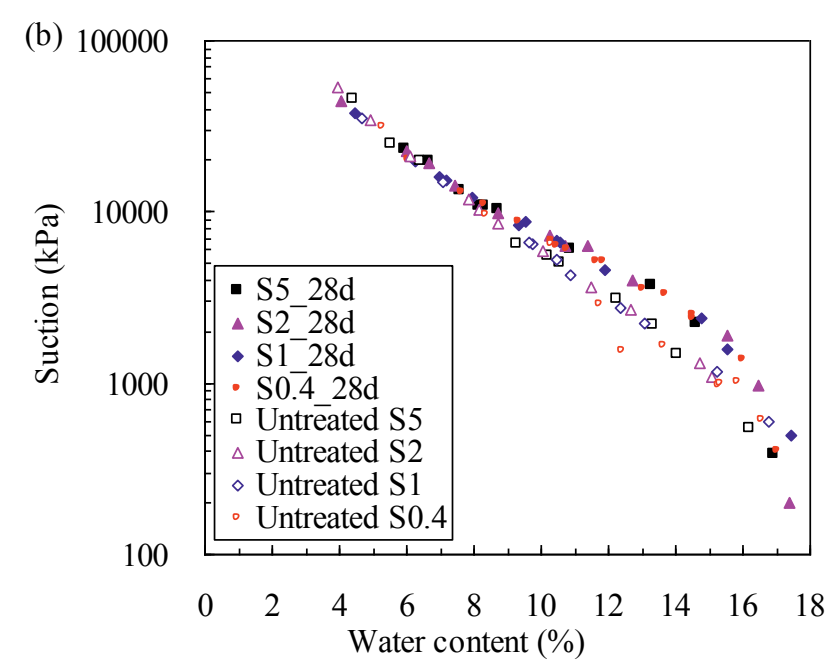

(c) 100000

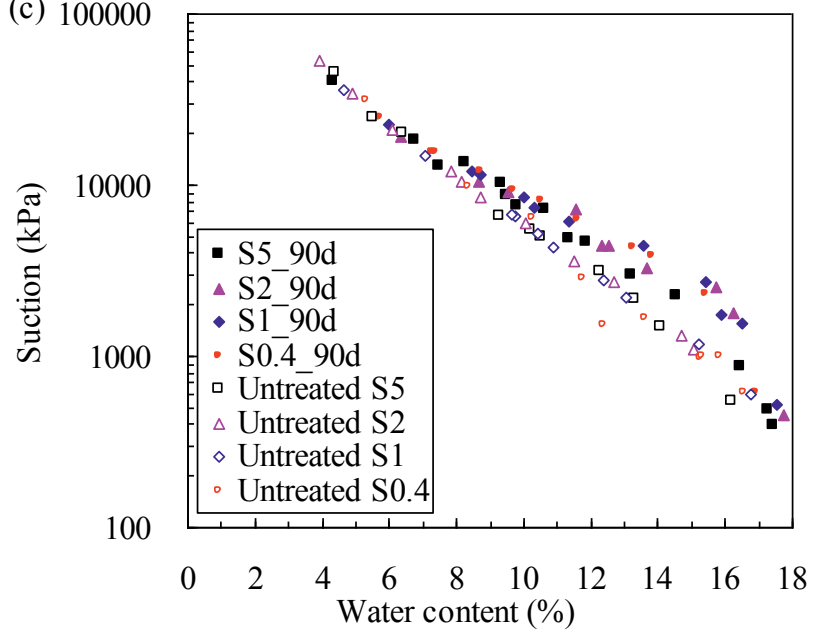

Figure 3. Water retention curves of $2 \%$ lime-treated soils during different curing times in comparison with that of untreated soils.

\section{Discussions}

The main drying paths of water retention curves measured on untreated soils with different sizes of aggregates show a similar behaviour. Romero et al. [13] explained that low water content range is related to intra and inter-cluster water, and the corresponding linear relationship between the logarithm suction and water content is controlled by the soil intra-aggregate microstructure. Wang et al. [12] indicated that the aggregate size mainly affect the macro-pores (interaggregate pores) rather than the micro-pores (intraaggregate pores). In fact, different aggregate sizes form different contacts among soil aggregates and different size of inter-aggregate pores, which govern the lower suction range and air entry value. When at lower water content levels, main de-saturation takes place in the intraaggregate pores (referring to the remove of inter-cluster and intra-cluster water), which is controlled by the clay structure.

The increase of water retention capacity of limetreated soils observed during curing can be attributed to the production of cementitious compounds during curing. These cementitious compounds gradually filling the interaggregate pores over time, in the way of coating on the surface of soil aggregates [14-15]. Thus, the size and connectivity of the inter-aggregate pores are modified; some entrances of small intra-aggregate can also be blocked, changing some non-constricted pores to constricted pores and increasing the possibility of inkbottle pores. These pores modified by the cementitious compounds can improve the water retention capacity of soil by retaining water in the wide inner pores upon drying. And the smaller the narrow openings of the link bottle pores, the higher the suction values needed to desaturate the soil [12, 16-18].

Pozzolanic reactions are largely time-dependent. Very slight increase of water retention capacity is observed on the lime-treated soils at the curing time of $t=7$ days, owing to the small quantity of cementitious compounds generated during that short curing time. With the increase of curing time, water retention capacity is continuously increased. At the curing time of $t=90$ days, the water retention curves of treated soils become an S-shaped character with a higher suction values in the range from ca $860 \mathrm{kPa}$ to $13 \mathrm{MPa}$. In the long curing period, larger quantity and better distribution of cementitious compounds are allowed to occur, resulting in an evident increase in the water retention capacity of soil.

Aggregate size effect is observed significant on the treated soils after a long time of curing ( $t=90$ days). Whereas, this effect is not evident in the short curing duration ( $t=7$ and 28 days). This is also in agreement with the time-dependent pozzolanic reactions. In short period, only a small quantity of cementitious compounds is generated, increasing the water retention capacity very slightly. Under this circumstance, it is difficult to distinguish the different effects induced by different size of aggregates.

In the soil prepared with small aggregates, there are more contact areas between soil aggregates and lime particles, compared with that with large aggregates. Under this circumstance, more cementitious compounds are expected to be generated or a better distribution of cementitious compounds is formed in a long curing period, which is beneficial to the modification of microstructure as discussed above, resulting in a larger improvement on the water retention capacity.

In the high suction range (more than $13 \mathrm{MPa}$ ), the water retention properties of untreated soils and that of treated soils even in the long curing period are similar. Note that the cementitious compounds mainly coating on the surface of soil aggregates. Even though some entrance of intra-aggregate pores can be blocked and constrict pores can be developed, most inter- and intracluster water may not be modified. When de-saturation takes place in this suction range, most inter-cluster water and some intra-cluster water begin to remove, leads to a similar behaviour between untreated soils and treated soils. 


\section{Conclusion}

Water retention curve measurement on both lime-treated soil and untreated soil compacted dry of optimum were performed. Aggregate size effect on the water retention property of treated soil was emphasized in this study. Based on the obtained results, the following conclusions can be drawn:

- Aggregate size effect is insignificant on the water retention curve of untreated soil in the studied suction range, which can be mainly controlled by the intraaggregate pores.

- Lime addition improves the soil water retention capacity with the increasing of curing time, due to the generation of cementitious compounds which modify the soil microstructure.

- In a long curing period, aggregate size effect on water retention property of lime-treated soil becomes significant in the suction range from ca $860 \mathrm{kPa}$ to ca 9 $\mathrm{MPa}$ : treated soils prepared with smaller aggregate size (S0.4 and S1) have a relatively higher water retention capacity rather than that prepared with larger aggregate size (S5). This attributes to more quantity and better distribution of cementitious compounds which are expected in the soil of small aggregates, because of the large contact areas between aggregates and lime.

\section{Acknowledgements}

The authors would like to thank the China Scholarship Council (CSC) and Ecole des Ponts ParisTech for their financial support. They would also gratefully acknowledge the helpful support provided by the European Commission via the Marie Curie IRSES project GREAT - Geotechnical and geological Responses to climate change: Exchanging Approaches and Technologies on a world-wide scale (FP7-PEOPLE2013-IRSES- 612665).

\section{References}

1. D.I. Boardman, C.D.F. Rogers, S. Glendinning, Géotechnique, 51, 533-543 (2001)

2. G. Russo, Advanced Experimental Unsaturated Soil Mechanics (Taylor \& Francis, London, 391-396. 2005)

3. N.C. Consoli, L.S. Lopes, K.S. Heineck, J. Mater. Civ. Eng., 21, 210-216 (2009)

4. M. Al-Mukhtar, A. Lasledj, J.F. Alcover, Appl. Clay. Sci., 50, 191-198 (2010)

5. A.M. Tang, Y.J. Cui, M.N. Vu, Géotechnique, 61, 421-429 (2011)

6. T.D. Tran, Y.J. Cui, A.M. Tang, M. Audiguier, R. Cojean, J. Rock Mech. Geotech. Eng. 6, 399-404 (2014)

7. I. Bozbey, E. Guler, Waste Manage., 26, 1277-1286, (2006)

8. A. Kavak, A. Akyarh, Environ. Geol., 51, 987-997 (2007)

9. D.V. Tedesco, PhD Thesis at the University of Cassino, (Cassino, Italy, 2006)

10. S. A. A. Khattab, L.Kh.I. Al-Taie, Unsaturated Soils, ASCE, 1671-1682 (2006)

11. D. Deneele, K. Lemaire, Terrassement Durables Ouvrages En Sols Traités, 2008-2012 (2012)

12. Y. Wang, Y. J. Cui, A. M. Tang, C. S. Tang, N. Benahmed, Geotech. Lett., 5, 269-274 (2015)

13. E. Romero, A. Gens, A. Lloret, Eng. Geol., 54, 117127 (1999)

14. K. Lemaire, D. Deneele, S. Bonnet, M. Legret, Eng. Geol., 166, 255-261 (2013)

15. B. Shi, Z. Liu, Y. Cai, X. Zhang, J. Mater. Civ. Eng., 19, 99-104 (2007)

16. D.V. Tedesco, G. Russo, Unsaturated Soils: Advances in Geo-Engineering, Taylor \& Francis, London, 277-282 (2008)

17. M. Cecconi, G. Russo, Unsaturated Soils: Advances in Geo-Engineering, Taylor \& Francis, London, 271276 (2008)

18. G. Russo, S. Vecchio, G. Mascolo, Experimental Unsaturated Soil Mechanics, Springer Berlin Heidelberg, 49-56 (2007) 